\title{
Physiological model of one materialized human thought
}

\author{
Victoria Kondratenko \\ V.M.Glushkov Institute of Cybernetics of NAS of Ukraine \\ Glushkov Avenue 40, Kyiv, Ukraine, 03037 \\ science.and.life@gmail.com, orcid.org/0000-0003-1577-6701
}

Received on 19.04.2018, accepted after revision on 12.12.2018

DOI: 10.31493/tit1812.0304

\begin{abstract}
In this article, the creation in the second signal system of a correct reflex ring - physiological model of one of the materialized elementary, or compound human thoughts - is shown on a specific example. As tools, functionally full formal language and predicate logic language are used. The methodology is described in the Theory of axiomatic modeling of Kondratenko [1]. As any other functional problem in any domain, according to the Theory, the problem is interpreted in mathematical logic as a theorem which is subject to proof. The reflex ring is physiological model of one of materialized elementary, or compound, thoughts of the specific person, as the ring represents a fragment of neural network of the person. The logical work of concepts of knowledge reflected in concepts No.1 - 7, is guaranteed to provide the creation of the correct reflex ring having the property of "being physiological model of one of the materialized elementary, or compound thoughts of a person". At reflection on visual carriers of any concrete functionally complete sense received in the course of knowledge of the natural and man-made phenomena of the universe, only purely formulary texts are an ideal format in terms of quantity of the symbols necessary for these purposes. Even the axiomatic format of reflection of the specified meanings demands one-two orders more of symbols, not to mention a verbal format from which the order of magnitude of formulary symbols can exceed four in certain cases. Special importance is gained by this fact at reflection on visual carriers of biological and medical knowledge.
\end{abstract}

Key words: Axiomatic modeling, artificial intelligence, mathematical logic, thinking, formalization.

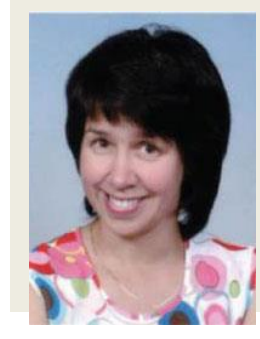

Victoria Kondratenko

Researcher of the Methods and technological construction tools of the Intellectual program systems Department PhD, Ass. Prof.

\section{INTRODUCTION}

Relevance of a subject. More than two millennia, mankind has been trying to get into physiology of the thinking to understand the mysteries of this phenomenon and to establish the dialectic reasons and physical forces, organizing and managing continuously dynamics of thinking process of the person throughout all his life [2, 3, 4].

However, the problem is extremely difficult, and its knowledge is given to mankind by scarcely noticeable particles for decades. Here and at the moment it became clear that (Necessary knowledge) the mentality of the specific person according to the standard project of its genome in neural networks of the nervous system creates for each thought a separate reflex ring on the basis of code words [5] which identify physical quantities in reflex rings of the first signal system.

The thought is considered elementary and correct if it is expressed by one code word, in compliance to which one physical quantity in a 
separate reflex ring of the first signal system is put.

The most surprising circumstance is that those restrictions which are recorded in its genome, specifically in rules of creation of reflex rings in the second signal system, are not known to each specific person. In particular, the restriction which is not allowing the presence at a reflex ring of the second signal system of code words which do not have physical implementation in a format of a reflex ring of the first signal system.

Behind this restriction there is prohibition on use by the specific person of the nonmaterialized thoughts called hypothetical thoughts. Use of hypothetical thoughts in live matter is inadmissible since it inevitably leads to disaster in life activity of this matter.

Not everything is so simple also with reflex rings, both in the first signal system, and in the second signal system. As warning against illusiveness of simplicity in structure of rings, I include below only the functional diagram of correct reflex rings (Fig.1) and terms of their forming in the course of progressive evolution of a human body which is carried out by $\mathrm{Na}-$ ture.

In fact, correct reflex rings represent the closed systems of automatic control (CSAC) with necessary (for steady work!) negative feedbacks (rigid and flexible), program setting devices for adjustable physical quantity and the "intelligent" regulators calculating necessary value of adjustable value in the current conditions of the operating perturbations on adjustable physical quantity. In the functional diagram of a ring, the role of the programsetting device for adjustable physical quantity and the role of the "intelligent" regulator for this value are carried out by "the nervous center".

In a human body Nature spent more than 4 billion years to form the first signal system of modern level.

In a human body Nature spent more than one billion years to form of the second signal system of modern level.

And on forming of one reflex ring of a compound and correct thought in the second signal system, the person of average abilities will need, at least, several working days.

Rules of forming of compound thoughts in the socioeconomic systems of our planet were defined long ago. They specialize in profiles of socially useful activity $[6,7,8]$.



Fig.1. Function chart of a reflex ring

For scientific activity in the exact sciences, for example, these rules are formulated in the special science called mathematical logic. The purpose of knowledge of the exact sciences is only the logic of the cause and effect relations between the physical variables which are functionally fully characterizing one and all statuses of dynamic systems of any complexity.

\section{PURPOSE OF THE ARTICLE}

The purpose of the article consists in submission of the description of results of scientific knowledge of the phenomena and processes of the universe on the basis of the correct and materialized elementary and compound thoughts of scientists.

Concepts of knowledge of basic provisions of mathematical logic.

Concept No.1. Mathematical logic is a functionally full formal language which is specially intended for aphoristic (the greatest possible brevity and accuracy!) style of the description of a logical entity of the studied processes and the phenomena in the universe.

Concept No.2. During the solution of each specific logical problem, the described mathematical structure works with the fixed finite 
set of operands, to each of which the director of a task appropriated "true" or "false" value.

Concept No.3. Mathematical logic, being a functionally full mathematical structure, is equipped only with four logical actions:

- logical denial

- logical summing (disjunction)

- logical product (conjunction)

- logical following (implication).

Concept No.4. Every specific functional problem, subject to a solution, in any domain is interpreted in mathematical logic as a theorem which is subject to proof.

Concept No.5. Semantic filling of theorems is defined by the code words of monolingual dictionaries of that domain which possesses the problem functional problem subject to a solution.

Concept No.6. The modern science of mathematical logic is equipped with a formal method of $100 \%$ of reliability of the automatic theorem proving which does not even demand computer support $[9,10,11]$.

Concepts of knowledge of the highest mental function (HMF) of thinking as a part of HMF of human mentality.

Concept No.7. Thinking - as an informative process. Qualitative characteristics of thinking.

Thinking evolves from practical activities, from sensory perception, but goes far beyond its limits. In turn, the correctness of thinking is checked during practice.

At the level of the second signal system words are perceived and signals coming here are replaced with the speech. Therefore thinking is inseparably linked with speech, both internal, and external. Thinking creates concepts, their understanding and also their interrelations. Thinking operates with concepts which in the form are words, and, in fact - a result of cogitative operations. In turn, specification of verbal concepts can result from thinking.

Thinking takes place only when there is a problematic situation. If it is possible to manage in the old ways of action, then thinking is not required [12,13,14].

\section{Main types of thinking.}

In the process of the development of the mentality of a person in the course of his so- cialization, thinking consistently goes through four stages.

The first way of thinking of the child - subject-effective thinking (aged from 1 up to 3 years), that is, thinking in the form of practical actions. Small children learn the world around them and draw the first conclusions about its device, trying objects by hand, sorting them and breaking.

The following step - evident and figurative - thinking in the form of evident images and representations (visual, acoustical, tactile). It is most developed in ages from 4 up to 7 years, but remains also at adulthood. This thinking relies on practical reality, but can already create and store images which do not have a direct analog in feelings (fairy tale characters).

In figurative thinking which is most developed in artists, designers, advertisers, tailors, hairdressers and architects, materials for the solution of a problem are not concepts, but images - it is more often visual (for musicians acoustical). They are either taken from memory or recreated by imagination. The prevailing role in this type of thinking is played by the right hemisphere of the brain. The difference from the previous stage is wide use of verbal designs in formation and transformation of images and also use of abstract concepts.

Abstract and logical (abstract or conceptual) thinking works in the form of abstract concepts, symbols and figures. In this case the person operates with concepts, without dealing with the experience obtained by means of sensual organs.

For example, terms of ethics - "justice" and "conscience"; mathematical terms - "degrees" and "derivative"; economic terms - "balances" or "profit" are abstract concepts and cannot be perceived by the person directly his sense organs.

\section{Forms of thinking.}

The main forms of thinking [15] are: concepts, judgments and conclusions.

Concept - a thought in which the general, essential signs of objects and phenomena are reflected.

For example, the concept "person" includes such essential signs as work, bipedalism, the articulate speech, etc. The difference of a con- 
cept from representation consists that representation is always an image, and the concept is the thought expressed in a word. Besides, representation includes both essential, and insignificant signs, and a concept - only essential. The maintenance of concepts is revealed in judgments.

Judgment is reflection of communications between objects and phenomena or between their properties and features.

It is possible to construct the form of thinking following on complexity of two or more judgments - conclusion.

Conclusion is a connection between concepts or judgments that takes several judgments and produces a new judgment as a result.

\section{Cogitative operations.}

Process of thinking includes several operations: comparison, analysis, synthesis, abstraction, generalization, specification.

Analysis is mental partition of an object into the elements with their subsequent comparison. For example, the psychologist carries out the analysis of personal qualities of the client on the basis of results of the Kettel test.

Synthesis is association of separate components into a whole. It is usually adjoin to analysis. Continuing the previous example, we will imagine how the psychologist, after the analysis of several tests, builds the generalized psychological portrait of the person.

Abstraction is allocation of one party of a subject or phenomenon which in reality as separate entity does not exist. As a result of abstraction, concepts are formed. As an example, it is possible to take the concept "reliability" as the low probability of breakage of some kind of household appliances.

Generalization is allocation of the general essential properties in the compared objects. For example, having made the analysis of sales of separate grades of bread, the owner of a bakery comes to a conclusion that rich rolls, irrespective of their sizes and stuffing's are in highest demand.

Specification is an operation, the inverse of generalization, the allocation to a subject or a phenomenon of features, characteristic of it, which are not connected with common fea- tures of the corresponding class of subjects or phenomenon's. For example, the owner of a mini-bakery, having found out the increased demand for rich rolls, decides to bake their new look - with sesame and a strawberry stuffing.

Concept No.8. The knowledge in concepts No. $1-7$ provides functional completeness of this knowledge for the purpose of creation by the person of a correct reflex ring in his own second signal system, "being physiological model of one of the materialized elementary, or compound thoughts of this person" [5]. Additional and new knowledge of concept No. 8 is the statement: "being physiological model of one of the materialized elementary, or compound thoughts of this person".

Concept No.8 can be interpreted as the conclusion in the theorem in which hypotheses are concepts No.1 -7 .

\section{MODELING METHODOLOGY}

Modeling methodology is the theory of axiomatic modeling of Kondratenko and, in its framework, the Predicate logic of first order as the universal formal language intended for the description of all, known to modern science, logical relations between variables of states(9).

The target theorem can be formulated in the following statement:

The logical product of concepts of knowledge reflected in concepts No.1 -7 is guaranteed to provide creation of the correct reflex ring having the property of "being physiological model of one of the materialized elementary, or compound thoughts of a person"[16].

The property of "being physiological model of one of the materialized elementary, or compound thoughts of a person" by definition is true, so the ring represents a fragment of neural network of the person - the director of a task.

From now, all problem definitions should be presented in the language of a predicate logic of first order, with the description corresponding to methodology of the automatic theorem proving. 
For this purpose concepts of knowledge should be identified the term "axiom" with number of the corresponding concept of knowledge.

For the reflection of the target theorem in a formular form, each of the axioms is stated above in the context of article must be presented as a formula of a predicate logic of first order.

Axiom No.1. $p 1(X)$ where $p 1$ bears semantic loading of dialectic logic of a context of this axiom, and in brackets - subject variable $X$ identifies the organism of the abstract person.

Axiom No.2. $p 2(X)$ where $p 2-$ bears semantic loading of dialectic logic of a context of this axiom, and in brackets - subject variable $X$ identifies the organism of the abstract person.

Axiom No.3. $p 3(X)$ where $p 3$ - bears semantic loading of dialectic logic of a context of this axiom, and in brackets - subject variable $X$ identifies the organism of the abstract person.

Axiom No.4. $p 4(X)$ where $p 4-$ bears semantic loading of dialectic logic of a context of this axiom, and in brackets - subject variable $X$ identifies the organism of the abstract person.

Axiom No.5. $p 5(X)$ where $p 5$ - bears semantic loading of dialectic logic of a context of this axiom, and in brackets - subject variable $X$ identifies the organism of the abstract person.

Axiom No.6. $p 6(X)$ where $p 6$ - bears semantic loading of dialectic logic of a context of this axiom, and in brackets - subject variable $X$ identifies the organism of the abstract person.

Axiom No.7. $p 7(X)$ where $p 7$ - bears semantic loading of dialectic logic of a context of this axiom, and in brackets - subject variable $X$ identifies the organism of the abstract person.

Axiom No.8. $p 8(X)$ where $p 8$ - bears semantic loading of dialectic logic of a context of this axiom, and in brackets - subject variable $X$ identifies the organism of the abstract person.
On the basis of logical formulas of axioms No. $1-8$ the formula of the target theorem will have the following appearance:

$$
\begin{gathered}
(\forall X)(p 1(X) \wedge p 2(X) \wedge p 3(X) \wedge p 4(X) \wedge \\
\wedge p 5(X) \wedge p 6(X) \wedge p 7(X)=>p 8(X)) \\
\Rightarrow> \\
(\exists X)(p 1(X) \wedge p 2(X) \wedge p 3(X) \wedge p 4(X) \wedge \\
\wedge p 5(X) \wedge p 6(X) \wedge p 7(X)=>p 8(X))
\end{gathered}
$$

Denote by $F 1$ the formula

$$
\begin{gathered}
(p 1(X) \wedge p 2(X) \wedge p 3(X) \wedge p 4(X) \wedge \\
\wedge p 5(X) \wedge p 6(X) \wedge p 7(X))
\end{gathered}
$$

Then formula (1) becomes:

$$
\begin{gathered}
{\left[(\forall X)\left({ }^{\prime} \mathrm{I} F 1 \vee p 8(X)\right)\right]} \\
\Rightarrow> \\
{\left[(\exists X)\left({ }^{\prime} \mathrm{I} F 1 \vee p 8(X)\right)\right]}
\end{gathered}
$$

The structure of formula (2) contains two formulas connected by the implication symbol:

$$
\begin{aligned}
& F 2(X) \equiv[(\forall X)(' \mathrm{I} F 1 \vee p 8(X))] \\
& F 3(X) \equiv\left[(\exists X)\left({ }^{\prime} \mathrm{I} F 1 \vee p 8(X)\right)\right] .
\end{aligned}
$$

The theory of automatic theorem proving [14], in order to reduce formulas to the canonical format containing only axioms and three logical operations (conjunction, disjunction and negation), 27 formal rules are defined and proven, which describe equivalent transformation of formulas of first order predicate logic.

Two of them look as follows:

$$
\begin{aligned}
& (F 2(X)=>F 3(X)) \equiv\left({ }^{\prime} \mathrm{I} F 2(X) \vee F 3(X)\right) \\
& (F 2(X)=>F 3(X)) \equiv(F 2(X) \wedge ' \mathrm{I} F 3(X))
\end{aligned}
$$

One of the rules determines

$$
' \mathrm{I} \exists \equiv \forall
$$


One prescribes freeing the formula of all generality quantifiers if it doesn't contain any other quantifiers.

If one used four of these last rules, formula (2) becomes

$$
\left[{ }^{\prime} \mathrm{I} F 1 \vee p 8(X)\right] \wedge\left[\text { 'I }\left[{ }^{\prime} \mathrm{I} F 1 \vee p 8(X)\right]\right]
$$

Formula (3) represents conjunction of only two contrary components.

What demonstrates its discrepancy, but also demonstrates the validity of the theorem in general as the methodology of the automatic proof of theorems is based on a conclusion of discrepancy of a formula of the theorem in general.

Therefore, the theorem is successfully proved.

\section{CONCLUSION}

The logical work of concepts of knowledge reflected in concepts No. $1-7$, is guaranteed to provide the creation of the correct reflex ring having the property of "being physiological model of one of the materialized elementary, or compound thoughts of a person"[17]. At reflection on visual carriers of any concrete functionally complete sense received in the course of knowledge of the natural and manmade phenomena of the universe, only purely formulary texts are an ideal format in terms of quantity of the symbols necessary for these purposes[18]. Even the axiomatic format of reflection of the specified meanings demands one-two orders more of symbols, not to mention a verbal format from which the order of magnitude of formulary symbols can exceed four in certain cases[19,20]. Special importance is gained by this fact at reflection on visual carriers of biological and medical knowledge. Amount of fundamental meanings in these sciences such is that their description in a verbal format requires the quantity of symbols on two-three orders exceeding possibilities of long-term memory of a brain of an ingenious person.

\section{REFERENCES}

1. Kondratenko V.A., 2010. Creation of a uniform stereotype of a logical design of thinking for the substantial and formal proof of theorems. Kiev Scientific publication of Alephof, 267 (in Russian).

2. Nilsson N.J., 1982. Principles of artificial intelligence, Springer-Verlag Berlin Heidelberg, 476.

3. Russell S., Norvig P., 2009. Artificial intelligence: a modern approach, 3rd ed. Prentice Hall, 1152.

4. Turing A., 1950. Computing Machinery and Intelligence. Mind, Vol.59, No. 236, 433-460.

5. Anokhin P.K., 1998. Chosen works. Cybernetics of functional systems. Moscow, Medicine, 400 (in Russian).

6. Nazarenko O., 2018. Modeling the reliability of the recycled water supply system at global warming conditions. Transfer of Innovative Technologies, Vol.1(1), 50-57 (in Ukrainian).

7. Otradnov K, Volodymyr Shuliak, Sergii Kornieiev, 2017. Underwater wireless video communication in operations of AUV/UUVs new horizon of underwater explorations. Underwater Technologies, Vol.06, 46-56 (in Russian).

8. Bezverkhy O, 2016. Oscillations buoy-moored barrier systems on the waves. Underwater Technologies, Vol.03, 14-24 (in Ukrainian).

9. Kondratenko V.A., 2016. Creation of formal model of standard dialectic logic of automatic control of the anatomo-functional systems of a human body. The 5th International scientific and technical conference Information Systems and Technologies Kharkiv-Koblevo IST-2016 (on September 12-17, 2016), (in Russian).

10.Kondratenko V.A., 2014. A living matter in an image of formal models (From physiological heredity to intelligence with its assets). The collection of articles of the author, Kiev, Scientific publication of LLC, Yunik Print, 186 (in Russian).

11.Kondratenko V.A., 2015. Paradoxes of science of the twentieth century. The twenty first century - dialectic logic against mysticism, Kiev, Scientific publication Zadruga, 200 (in Russian).

12.Kondratenko V.A., 2016. Dialectic logic of management of the autonomic nervous system of the person. Computer mathematic, No.1, 125-133 (in Russian). 
13.Kondratenko V.A., 2017. Artificial intelligence. A plan and realities of the current time against the background of natural intelligence of the person. Kiev, Scientific publication Zadruga, 84 (in Russian).

14.Chen Ch., Li R., 1983. Chapter 5. Method of resolutions, Mathematical logic and automatic proof of theorem, Chin-Liang Chang, Richard Char-Tung Lee, Symbolic Logic and Mechanical Theorem Proving. Academic Press, Moscow, Science, 358 (in Russian).

15.Agadzhanyan N.A., Human physiology, 2003. (The textbook for medical higher education institutions), Agadzhanyan N.A., Tel L.Z., Tsirkin V.I., Chesnokova S.A., under the editorship of the academician of the Russian Academy of Medical Science Agadzhanyan and professor N.A. Tsirkin, the Medical book, N. Novgorod, NGMA Publishing house, 408 (in Russian).

16.Kondratenko V.A., 2016. Mathematical models of physiological processes of metabolism, reflex and intellectual activity head vegetable pulp of the person. Kiev, Scientific publication Zadruga, 128 (in Russian).

17.Guts A.K. Chapter, 2003. Method of resolutions, Mathematical logic and theory of algorithms, Omsk, Heritage. Dialogue Siberia, 108 (in Russian).

18.Mendelssohn E., 1984. Introduction to mathematical logic, Moscow, Nauka, 320 (in Russian).

19.Petrunia O., 2017. Ways of considering traditions when forming the system of maintenance in Ukraine. Underwater Technologies, Vol.07, 57-63 (in Russian).

20.Chernishev D., 2018. Analytical systems of engineering protection of territories as a component of Biosphere compatible construction Transfer of Innovative Technologies, Vol.1(1), 58-64 (in Russian).

\section{Физиологическая модель одной из материализованных мыслей человека}

\section{Виктория Кондратенко}

Аннотация. В статье демонстрируется на конкретном примере построение во второй сигнальной системе корректного рефлекторного кольца - физиологической модели одной из материализованных элементарных, либо составных мыслей человека. В качестве инструментария используется функционально полный формальный язык, язык логики предикатов. Методология описана в Теории аксиоматического моделирования Кондратенко [1]. Задача, как любая другая проблемная функциональная задача произвольной предметной области, согласно Теории, интерпретируется в математической логике в качестве подлежащей доказательству теоремы. Рефлекторное кольцо является физиологической моделью одной из материализованных элементарных, либо составных, мыслей конкретного человека, так как само кольцо представляет собой фрагмент нейронной сети человека. Логическое произведение концептов знаний, отраженных в концептах No.1 - 7, гарантировано обеспечит построение корректного рефлекторного кольца, обладающего свойством "являющегося физиологической моделью одной из материализованных элементарных, либо составных мыслей этого человека". При отражении на визуальных носителях любого конкретного функционально завершенного смысла, полученного в процессе познания природных и рукотворных явлений в мироздании, только чисто формульные тексты являются идеальным форматом с точки зрения количества символов, необходимых для этих целей. Даже аксиоматический формат отражения указанных смыслов требует на один-два порядка больше необходимых символов, не говоря уже о вербальном формате, который может превысить в некоторых случаях и четыре прядка формульных символов. Особую важность приобретает этот факт при отражении на визуальных носителях биологических и медицинских знаний.

Ключевые слова: аксиоматическое моделирование, искусственный интеллект, математическая логика, мышление, формализация. 